\title{
A NATUREZA JURÍDICA DA RELAÇÃO ENTRE MÉDICOS E HOSPITAIS: UMA ANÁLISE DA PEJOTIZAÇÃo
}

\author{
Miguel Kfouri Neto ${ }^{1}$ \\ Fioravante Bizigato Junior ${ }^{2}$ \\ Tiago Rafael de Souza ${ }^{3}$
}

\begin{abstract}
Resumo
O presente artigo tem como principal objetivo analisar a natureza jurídica da relação entre médicos e hospitais e, por sua vez, a ocorrência da chamada "pejotização", isso porque, com as mudanças socioeconômicas que assolam o país, empregadores/hospitais passaram a desvirtuar o contrato de emprego na tentativa de ocultar verdadeiros vínculos empregatícios, apelando para meios ardis, como a exigência de personalidade jurídica constituída como critério de contratação, surgindo assim um novo gênero ou uma nova nomenclatura atribuída a esta modalidade fraudulenta, a "pejotização". A referida terminologia é apresentada pela doutrina para qualificar as pessoas físicas que constituem uma personalidade jurídica própria para prestação de serviços em uma evidente relação de emprego. Diante disso, o estudo realizado realiza uma abordagem preliminar envolvendo o conceito e as características da relação de emprego, fazendo uma diferenciação desta com as demais relações de trabalho, além de apresentar as inovações provenientes da Lei 13.467/2017, que promoveu a reforma trabalhista. Na sequência, é analisado o fenômeno da "pejotização", abordando desde o seu conceito até as suas evidências no Brasil. Por fim, no último capítulo, faz-se uma ampla reflexão acerca de sua utilização nas relações entre médicos e hospitais, apresentando casos concretos e o entendimento jurisprudencial acerca do tema.
\end{abstract}

Palavras-chave: Pejotização. Médicos. Hospitais. Natureza Jurídica. Relação de Emprego.

\footnotetext{
${ }^{1}$ Pós-Doutor em Ciências Jurídico-Civis junto à Faculdade de Direito da Universidade de Lisboa (2013-2014). Doutor em Direito das Relações Sociais pela Pontifícia Universidade Católica de São Paulo (2005). Mestre em Direito das Relações Sociais pela Universidade Estadual de Londrina (1994). Bacharel em Direito pela Universidade Estadual de Maringá (1981). Licenciado em Letras-Português pela Pontifícia Universidade Católica do Paraná (1972). Professor-Doutor integrante do Corpo Docente Permanente do Programa de Doutorado e Mestrado em Direito Empresarial e Cidadania do Centro Universitário Curitiba.

${ }^{2}$ Fioravante Bizigato Junior Mestrando do Centro Universitário Curitiba - Unicuritiba programa de mestrado em Direito empresarial e cidadania, fiore.bizigato@gmail.com

3 Tiago Rafael De Souza, Especialista em Direito e Processo do Trabalho UEPG, Mestrando do Centro Universitário Curitiba - Unicuritiba programa de mestrado em Direito empresarial e cidadania, tiago_souza11@hotmail.com
} 


\section{INTRODUÇÃO}

No presente trabalho, será abordada a natureza jurídica do médico contratado sob constituição de pessoa jurídica, a qual é chamada de "Pejotização". A origem deste termo é derivada da abreviação (PJ) de Pessoa Jurídica empresarial, e vem sendo utilizado pela doutrina e pelos tribunais para denominar a fraude no contrato de emprego. Assim, sucintamente, a "pejotização" pode ser conceituada como uma prática trabalhista fraudulenta, utilizada para o desvirtuamento da relação de emprego efetivamente existente, que se "formaliza" com a determinação direcionada ao médico para a constituição de uma pessoa jurídica.

Nesse sentido, o artigo 129 da Lei nº 11.196/2005 viabilizou a contratação de serviços intelectuais e de natureza científica e artística, por meio da constituição de pessoas jurídicas. É neste cenário que se encontram inseridos os médicos, pois a natureza da sua profissão pode ser enquadrada como serviço intelectual, de modo que os empregadores (hospitais), com o intuito de fraudar o contrato de emprego, exigem do profissional a constituição de pessoa jurídica para a contratação.

O Direito do Trabalho no Brasil tem como princípio base à proteção do trabalhador, considerando-o hipossuficiente em relação ao empregador, hipossuficiência esta derivada da era escravocrata, em que se visualizava um regime de completa subordinação, sem o exercício de qualquer direito.

Após este período, mais especificamente no período da ditadura militar, se estabeleceu o regime democrático no Brasil, com a promulgação da Constituição Federal de 1988, tem-se a elaboração de um texto constitucional com a prevalência dos Direitos Humanos e Sociais, garantindo aos empregados uma maior proteção do estado, ele passa exercer um papel intervencionista sob o domínio econômico e admite a desigualdade entre as partes na relação de trabalho, assim cabe ao estado criar mecanismos de proteção aos empregados, para não ser conivente com a exploração do mais forte sobre o mais fraco. A maneira de restabelecer a igualdade substancial entre empregado e empregador seria criando parâmetros para compensar a hipossuficiência do empregado frente aos abusos do empregador. A partir disso a nossa carta magna garantiu no seu capítulo II destinado aos Direitos Sociais no seu artigo $7^{\circ}$, as garantias fundamentais ao trabalhador.

Com o advento da globalização, surgem no Direito do Trabalho novas formas de labor, a necessidade do setor empresarial em reduzir custos, e a alta taxa tributária do país é um campo fértil para a precarização das formas de trabalho. É nesse sentido que a pejotização surge como mecanismo de contratação dos médicos pelos hospitais sem o vínculo empregatício. 
A evolução dos Direitos Fundamentais da sociedade e a tecnologia transformaram o meio jurídico, bem como o Direito do Trabalho, ao passo se fez necessária também a evolução normativa acerca das situações fáticas apresentadas.

No sentido desta evolução econômica, social e jurídica, é que acabam por ocorrer formas fraudulentas de contratação pelos tomadores. É neste cenário que se encontra o médico, que por vezes é obrigado a prestar serviços na forma de uma evidente relação de emprego, mascarada por uma suposta relação jurídica de prestação de serviços entre pessoas jurídicas, alcançando-se um panorama de supressão de direitos fundamentais e verbas trabalhistas.

Fato é que se trata de uma distinção tênue entre autonomia e subordinação dos médicos em relação aos hospitais e vice-versa, que só restará evidenciada na análise individual de cada caso.

Dessa forma, sob esta perspectiva que o presente trabalho busca analisar a relação existente entre médicos e hospitais, a fim de contextualizar o panorama existente e, por seu turno, verificar em que medida a "pejotização" eventualmente ocorrida caracteriza a fraude da relação de emprego e, consequentemente, a supressão de direitos fundamentais dos empregados.

\section{RELAÇÃO DE EMPREGO}

\subsection{CONCEITO E CARACTERÍSTICAS}

No âmbito trabalhista identifica-se o contrato de trabalho sob dois prismas, o contrato de trabalho como relação de trabalho e o contrato de trabalho tendo como conteúdo uma relação de emprego (cabe destaque aqui que alguns doutrinadores como Delgado (2014), endente ser a denominação correta: contrato de emprego), sendo este último, espécie do gênero relação de trabalho. Assim o médico pode estar inserido como trabalhador liberal, situação na qual estaria inserido em uma relação de trabalho como profissional autônomo e assim fora da aplicação da CLT, porém pode ocorrer a contratação com hospitais na forma de uma relação empregatícia e assim regido pelas normas trabalhistas, com os seus conteúdos e requisitos que serão analisados a seguir.

Para melhor enxergar a verdade real acerca do enquadramento do médico junto aos hospitais é necessário a distinção da relação de trabalho com a relação de emprego, bem como a compreensão dos requisitos caracterizadores desta última. As relações jurídicas entre as partes se manifestam através da manifestação da vontade, no contrato de trabalho não é diferente, as 
partes pactuam suas vontades, bem como suas prestações. Para que o médico se configure como empregado é necessário o vínculo empregatício, o qual se configura com a presença dos quatro requisitos característicos da relação de emprego.

Nosso ordenamento jurídico vigente a CLT em seu artigo $3^{\circ}$ traz uma definição de empregado ${ }^{3}$. A partir deles cabe análise de cada requisito para a verificação ou não do vínculo empregatício.

A pessoa física referida no artigo supra pode ser entendida como pessoa natural, Delgado (2014, p.292) esclarece que "os bens jurídicos tutelados pelo Direito Do Trabalho (vida, saúde, integridade moral, bem-estar lazer, etc.) importam à pessoa física, não podendo ser usufruído por pessoas jurídicas[...]”. Neste sentido ressalta Nascimento (2003, p.526) "a pessoa jurídica jamais poderá executar o próprio trabalho, fazendo-o por meio de pessoa físicas e porque o Direito Do Trabalho protege o trabalhador como ser humano[...]".

A importância da doutrina em classificar a pessoa física como requisito da relação de emprego, se mostra muito eficaz no presente trabalho, pois o fenômeno da pejotização em suma, transforma, ou obriga a pessoa física a constituir uma pessoa jurídica na relação de emprego.

O segundo elemento fático-jurídico da relação de emprego a pessoalidade guarda certa semelhança com o analisado anteriormente, mas com ele não se confunde, pois, a pessoalidade traz a ideia da prestação de serviço pessoalmente feita pelo obreiro com a no sentido de pessoa natural, sendo assim a prestação de serviços é intuito personae, ou seja, não podendo ser substituída por outrem. Discorre Delgado (2014, p.293) “a relação jurídica pactuada ou efetivamente cumprida deve ser desse modo intuito personae com respeito ao prestador de serviços, que não poderá assim fazer-se substituir intermitentemente por outro trabalhador ao longo da concretização dos serviços pactuados".

No presente trabalho a pessoalidade pode ser dialeticamente compreendida no seguinte sentido: o médico contratado como pessoa jurídica, caso fosse admitida essa forma de contratação em suposição, poderia se fazer substituir por outro, porém o que ocorre na pratica é o inverso, ele é contratado como PJ, porém lhe é exigido a pessoalidade no desenvolvimento de suas tarefas, à ele é imposto a prestação de serviço pessoalmente não podendo se fazer substituir, demostrando assim o requisito de uma relação empregatícia.

\footnotetext{
${ }^{3}$ CLT - Art. $3^{\circ}$ - Considera-se empregado toda pessoa física que prestar serviços de natureza não eventual a empregador, sob a dependência deste e mediante salário.

Parágrafo único - Não haverá distinções relativas à espécie de emprego e à condição de trabalhador, nem entre o trabalho intelectual, técnico e manual.
} 
A natureza não eventual a qual se refere o artigo alhures se entende como habitual, sendo assim o trabalho prestado pelo empregado deve-se orientar pela atividade normal da empresa, bem como a continuidade na relação empregatícia.

O embate do trabalho eventual e não eventual se perdura a tempos na doutrina, compondo assim várias teorias acerca da habitualidade do trabalho prestado, orienta a doutrina, que mesmo o obreiro não trabalhando todos os dias, esse serviço pode se tornar habitual, desde de que esteja pré-determinado a prestação do labor para o mesmo tomador. Os médicos, portando segundo o requisito acima, mesmo que laborem de maneira descontínua no hospital como por exemplo em regimes de escalas, ou plantões, a atividade será considerada continua, desde de que esteja pré-determinado pelos seus superiores os dias no qual prestará o serviço.

O penúltimo requisito da relação empregatícia é a onerosidade, observada no artigo $3^{\circ}$ da CLT como "mediante salário" habitualmente entendida. A onerosidade aqui deve ser pautada como contraprestação ao labor prestado pelo obreiro, por se tratar o contrato de trabalho bilateral e sinalagmático e oneroso; a ideia do sinalagma como as obrigações das partes pactuadas no contrato, sendo a do tomador o devido pagamento, e do obreiro a prestação dos serviços.

Cabe o adendo, segundo a doutrina o respectivo elemento não deve ser pautado sob a ótica do trabalho realizado, ou pela ótica do tomador de serviços. Delgado (2014, p.299)

O último requisito da relação empregatícia a ser analisado, e o mais importante, a subordinação.

Como será abordado a subordinação em suma seria a submissão do obreiro as ordens do tomador, deve-se contextualizá-la nas diversas formas existentes para a correta observância da sua incidência na relação entre médico e hospital. A correta observância acerca da subordinação permite ao operador do direito discriminar as várias situações fáticas jurídicas existentes em nosso ordenamento.

O trabalho subordinado, é a antítese do trabalho autônomo, a ideia de subordinação como sujeição as ordens do tomador podem ser observadas em códigos, como no italiano, que diferencia o trabalho autônomo do subordinado como assinala Nascimento (2003, p.369) "está no códice Civile da Italia (1942) que no livro quinto difere o "prestatore di lavoro subordinato" (art.2094) do "lavoro autônomo" (art.2.222) ", sendo na doutrina italiana a divisão do trabalho autônomo X subordinado tentando diferenciar as duas categorias, visto que as normas aplicáveis serão diversas, contribuição notável também é da economia na subordinação pois traz a ideia fundada no modelo taylorista o qual caracteriza-se pela ênfase 
nas tarefas, objetivando o aumento da eficiência ao nível operacional do trabalho, priorizando a redução dos custos entendidos no esforço. Orientado por Frederick Winslow Taylor, o modelo tem como ponto principal a analise cientifica do trabalho, estruturada pelo estudo dos tempos e movimentos e pela consequente definição do tempo-padrão, tendo como objetivo a fixação cientifica dos ritmos produtivos pela simplificação do trabalho, enquadrando o trabalhador com engrenagem do sistema produtivo, segundo uma direção cientifica do trabalho.

Sobre o conceito da subordinação ${ }^{4}$ discorre Delgado: (2014, apud FERREIRA P.1621) "Subordinação deriva de sub (abaixo) e ordinare (ordenar)", traduzindo a noção etimológica de estado de dependência ou obediência em relação a uma hierarquia ou valores.

O conceito acima abordado pelo Autor transmite a ideia de subordinação no Direito Do Trabalho sob um prisma objetivo atuando sobre o modo de realização da prestação de serviços, e não sob o prisma subjetivo recaindo sobre a pessoa do trabalhador, criando um estado de sujeição. Analisar a subordinação em cada caso é observar o modo como o trabalho é prestado, e não a sua forma denominada. Cabe ressalva que a nossa legislação celetista no seu artigo $3^{\circ}$ no trecho em que descreve: "sob dependência deste..." a ideia é referir-se à subordinação, devendo ser interpretado o trecho acima de forma mais correta como: "mediante subordinação". Assim no Brasil o legislador adotou a subordinação objetiva se baseando no modo de como os serviços são executados.

No decorrer dos anos a subordinação assumiu várias facetas, em anos atrás tínhamos a subordinação técnica do tomador, onde ele possuía a inteligência técnica da prestação de serviços, hoje superada pela tecnologia e seus avanços observamos que por diversas vezes quem detém o conhecimento técnico é o empregado, Delgado (2014) afirma que a fragilidade da noção de dependência técnica é flagrante, esclarece o autor que a referida dependência não corresponde sequer, a uma correta visualização do processo organizativo da empresa, visto que muitas vezes o empregador contrata o saber (e seus agentes) exatamente por não possuir controle individual sobre ele. Pode-se afirmar que também, está superada a ideia de subordinação econômica do empregado. Destaca Delgado: $(2014$, p.305) "contudo ainda que o critério econômico tenha irrefutável validade sociológica ele atua como elemento externo, incapaz, portanto, de explicar, satisfatoriamente, o nexo preciso da assimetria poder de direção/subordinação".

\footnotetext{
4 "Subordinação deriva de sub (abaixo) e ordinare (ordenar)", traduzindo a noção etimológica de estado de dependência ou obediência em relação a uma hierarquia ou valores. FERREIRA Aurélio Buarque de Holanda. Novo dicionário da Língua Portuguesa. 2.ed.Rio de Janeiro: Nova Fronteira, 1986. p. 1621
} 
A intensa modificação no mercado de trabalho e suas evoluções levam a uma análise criteriosa acerca da subordinação que segundo a doutrina apresenta certas dimensões que merecem o nosso apreço, sendo elas: clássica, objetiva e estrutural.

A subordinação clássica ou tradicional é aquela pela qual o trabalhador comprometese a acolher o poder de direção empresarial, referente ao modo de realização da prestação laborativa, destacando as ordens recebidas pelo mesmo na prestação de serviço, está é aquela subordinação original do poder do patrão sobre o empregado derivada da antiga servidão. Já a objetiva se manifesta pela integração do obreiro nos fins lucrativos do empreendimento do tomador. Delgado (2014) citando Paulo Emilio Ribeiro de Vilhena por fazer esta vinculação da subordinação ao critério exclusivamente objetivo: sendo o poder jurídico sobre atividade e atividade que se integra na empresa, esclarece ainda, que a subordinação pode traduzir uma relação de coordenação ou de participação integrativa ou colaborativa, na qual a atividade do empregado segue em harmonia a atividade da empresa, e dela recebe as ordens ou movimentos, sendo como essencial na subordinação objetiva a integração do trabalhador e seu labor aos objetivos da empresa.

A última dimensão da subordinação é a estrutural que se manifesta pela inserção do trabalhador na dinâmica do tomador independente de receber ordens diretas ou não. Martinez (2013, p.149) entende que a subordinação estrutural é caracterizada pela dispensabilidade de ordens direta (subordinação direta) do empregador para a formação do vínculo entre os efetivos beneficiários dos serviços contratados" No entendimento de Delgado (2014, p.306) está dimensão da subordinação, não importa que o trabalhador se harmonize (ou não) aos objetivos do empreendimento, nem que receba ordens diretas das especificas chefias deste: o fundamental é que esteja estruturalmente vinculado à dinâmica operativa da atividade do tomador de serviços.

Tão singela é classificação de trabalho subordinado/autônomo, que ao longo dos anos dada a evolução, e uma necessária adequação do direito do trabalho, surgiu a chamada parasubordinação ou coordenação, tratando de um modelo intermediário. Pereira (2013, p. 59 apud CASSAR) conceitua: “A parasubordinação é sinônimo de subordinação e designa o estado de sujeição do trabalhador que não é empregado, podendo ser autônomo, eventual ou qualquer outra espécie".

Na doutrina italiana já se distinguia a subordinação da coordenação, afirmando que a mesma denota a ideia de utilizar organicamente a prestação do trabalhador no âmbito da empresarial. 
A análise da subordinação se torna imprescindível na regulação do vínculo empregatício entre médicos e hospitais, pois muitas vezes não conseguimos enxerga-las de plano. Pode-se entender, todavia, que embora o médico exerça atividade altamente qualificada e, por essa razão, acha-se em grau quase insignificante de subordinação técnica, ele permanece prestando serviço por conta alheia, desprovido da propriedade dos meios de produção, e, portanto, a cargo do poder diretivo do tomador, tendo apenas sua força de trabalho colocada à disposição dos hospitais. A contextualização das formas em que podem ocorrer, bem como seus efeitos nos vislumbram uma melhor compreensão, saindo daquela ideia clássica de submissão as ordens empregatícias.

\subsection{Inovações da Lei $n^{0} \mathbf{1 3 . 4 6 7 / 2 0 1 7}$}

Com o advento da reforma instituída pela lei $\mathrm{n}^{\mathrm{o}} 13.467 / 2017$, foi questionado se a referida lei liberaria em tese a pejotização. Nesse sentido cabe a análise da reforma sob dois aspectos: o novo dispositivo 442-B CLT o qual discorre: "a contratação do autônomo, cumpridas por este todas as formalidades legais, com ou sem exclusividade, de forma contínua ou não, afasta a qualidade de empregado prevista no art. 3 desta Consolidação" a problemática deste artigo refere-se a sua interpretação literal, pois se assim fosse poderia admitir-se a contração de trabalhador na qualidade autônomo, mais na prática figuraria com os requisitos de uma relação de emprego.

$\mathrm{O}$ artigo acima descrito, deve ser interpretado ou enquadrado à aquelas situações de difícil visualização, ou zona cinzenta como querem os doutrinadores, no sentido de que, não estando todos os requisitos da relação de emprego, ou tendo apenas um deles, mesmo com exclusividade e habitualidade, podemos estar diante de uma relação autônoma, esse seria a correta interpretação do texto legal; observa-se que a intenção do artigo supra é reafirmar, que o importante é a presença (ou não) dos elementos fático-jurídicos da relação de emprego, ao invés da simples situação formal conferido ao contrato entre as partes.

O outro aspecto da reforma a ser analisado diz respeito a terceirização de atividade fim por parte da empresa, nesse sentido devemos nos ater ao fato de que primeiramente, para estarmos diante da terceirização, deve-se necessariamente existir uma relação triangular entre as partes figurantes na relação jurídica: o tomador de serviços, a prestadora e o obreiro, o tomador na terceirização contrata diretamente com a empresa prestadora de serviços, a qual dispõe de quadros de funcionários para prestação das atividades. Na pejotização ocorre uma 
relação bilateral, em que a empresa contrata diretamente com a pessoa física (jurídica), note-se, que por mais semelhantes que sejam esses institutos, eles se diferenciam. Entende-se que a nova Lei de Terceirização em nada altera a legalidade ou não da prática da pejotização; pois, apesar de a Lei $n^{\circ}$ 13.429/2017, flexibilizar a terceirização da atividade-fim das empresas, estas continuam não podendo contratar pessoas jurídicas para prestação de serviços diretamente para a tomadora, pois estariam descaracterizando a relação de emprego, sob pena de ser acusada de violação a legislação trabalhista.

\section{PEJOTIZAÇÃO}

\subsection{Conceito e Características}

O mundo do trabalho sofreu grande transformação a partir da globalização mais especificamente na década 90. Com a crise no mercado de trabalho exigiu-se das empresas uma nova forma de produção, baseado na transformação do trabalho, é nesse sentido que surgem na Europa novas categorias de empregos como o trabalho a tempo parcial, e a terceirização. Essa nova busca por uma adequação ao mercado atingiu a classe trabalhadora, o mercado passa a exigir um trabalhador mais qualificado para otimização do tempo e de seu serviço, ao passo disso, essas mudanças buscadas pelo setor empresarial quebram o paradigma protetivo do trabalhador, é dado a ele mais autonomia diminuindo a sua subordinação em relação ao empregador.

A origem do termo pejotização é derivada da abreviação (PJ), de Pessoa Jurídica Empresarial, o termo vem sendo utilizado pela doutrina e pelos tribunais para denominar a fraude ao contrato de emprego. A pejotização é um fenômeno frequente no século XXI nas relações entre empregador e empregado. Assim, o tomador exige do seu empregado, que constitua uma pessoa jurídica como exigência para ingresso no emprego o objetivo de prestar seu trabalho, ou faz o seu desligamento da empresa, para recontrata-lo como pessoa jurídica, o empregador contrata com uma pessoa jurídica assegurando os mesmos serviços prestados por uma pessoa física, entretanto, sem o vínculo de empregatício.

Trata-se de uma forma de desvirtuar a relação de emprego contida na CLT, a qual descreve que um dos requisitos necessários para caracterizar a existência da relação de emprego é a prestação de serviços por pessoa física. Assim, em regra, caso haja prestação por pessoa jurídica, não há configuração de relação de emprego. 
A pejotização pode ser considerada uma fraude as normas impostas pelo ordenamento jurídico brasileiro, quando se reconhecer que na verdade se trata de uma relação de emprego, estando presentes todos os requisitos desta, e que os direitos trabalhistas do empregado estão sendo mascarados por meio da pessoa jurídica. Pode-se concluir que pejotização é a forma pela qual o empregado constitui pessoa jurídica em seu nome ou de outrem, e contrata posteriormente com o empregador, prestando os mesmos serviços, entretanto, sem configurar relação de emprego já que, aparentemente, trata-se de contrato civil celebrado entre pessoas jurídicas para prestação de serviços e não entre pessoa física e jurídica.

\title{
3.2 Utilização no Brasil
}

A prática da "pejotização" ganhou campo no Brasil coma adoção da Lei n 11.196/2005, prevendo seu artigo 129:

\begin{abstract}
Para fins fiscais e previdenciários, a prestação de serviços intelectuais, inclusive os de natureza científica, artística ou cultural, em caráter personalíssimo ou não, com ou sem a designação de quaisquer obrigações a sócios ou empregados da sociedade prestadora de serviços, quando por esta realizada, se sujeita tão-somente à legislação aplicável às pessoas jurídicas, sem prejuízo da observância do disposto no art. 50 da Lei no 10.406, de 10 de janeiro de 2002 - Código Civil.
\end{abstract}

Assim, o art. 129, da Lei supra, supostamente autorizaria a contratação de trabalhadores para a prestação de serviços intelectuais através de pessoa jurídica, significando, também, como incentivo fiscal tanto para os trabalhadores como para os empregadores. Com base neste artigo os defensores da "pejotização", como relação de trabalho lícita, passaram a entender que as vantagens nela contida pela norma concedem ao obreiro e ao empresário uma variante de escolha do modo de vinculação na prestação de serviços intelectuais em detrimento à legislação trabalhista vigente, nesse sentido os empregados se beneficiariam, por terem uma carga tributária menor, podendo ainda deduzir as despesas da pessoa jurídica, bem como o desconto previdenciário. Trata-se assim de possibilidade de contratação legalmente autorizada, que ressalta os princípios da livre iniciativa, auto-organização e liberdade de contratação.

Diante da previsão legal, empregadores passaram a contratar cada vez mais pessoas físicas trajadas de personalidade jurídica para a prestação de serviços intelectuais e também, outros tipos de trabalhadores, se achando amparados na premissa do art. $7^{\circ}$, XXXII, da 
Constituição de 1988 e pelo parágrafo único do art. $3^{\circ}$, da CLT, os quais mencionam que não deve haver distinção entre o trabalho intelectual, técnico e manual.

Portanto, os defensores da "pejotização", como relação trabalhista lícita, apregoam que a referida lei trouxe a possibilidade de opção para os trabalhadores se transformarem em pessoas jurídicas, deixando de lado a condição de empregado. Alguns doutrinadores tem o entendimento de que a lei estaria disponibilizando, conforme critérios de conveniência e oportunidade, as partes envolvidas na prestação de qualquer modalidade de serviço, a opção de escolha da espécie de relação que irão firmar. Nessa corrente que defende a "pejotização", como relação de trabalho lícita, estão autores como Robortella. Em seu artigo denominado: Novo Conceito de Proteção - Direitos Humanos no Trabalho, trabalha uma nova configuração do trabalhador subordinado, defende ele, (como já mencionado como tendência do mercado de trabalho atual), uma nova adequação do Direito do Trabalho, rompendo com o princípio protetor, e estendendo a manifestação da vontade do trabalhador. O autor menciona, que a não observância desse fenômeno, de novas formas de contratação representará aumento considerável do trabalho informal. Por outro lado, defende que com a regulamentação haverá o aumento do trabalho regular, com uma proteção maior do Direito do Trabalho, embora mitigada, ampliando, assim, o número de oferta de trabalho e de arrecadação. Após análise da obra acima citada percebe-se ser o autor favorável a utilização de contratos de natureza civil, como a "pejotização", para trabalhadores de alta qualificação, pois segundo seu entendimento, o trabalhador com alta formação, e prestadores de serviços com elevado espírito empreendedor não se sentem estáveis com os limites da relação de emprego, refere-se, que esses altos profissionais não podem ser submetidos à uniformidade da legislação trabalhista, sendo caracterizados como empregados, já que quando no livre exercício da autonomia da vontade voltam-se para o trabalho em regime de autônomo ou com a constituição de empresas prestadoras de serviços.

No tocante a Lei n ${ }^{\circ}$ 11.196/2005 deve-se observado que é uma Lei de cunho tributário e não trabalhista sendo assim, caso o trabalhador se encaixe na modalidade de prestação de serviços prevista, será sem dúvidas pessoa jurídica, usufruindo dos incentivos fiscais e previdenciários conferidos por ela, passando a ser regido, pelo regime civil, sem a aplicação de qualquer lei trabalhista. Portanto, ao se tratar de contrato civil, tendo suas cláusulas contratuais respeitadas conforme a legislação própria, com as ausências dos requisitos da relação de emprego se estará diante de uma relação de autônomo, sendo possível a aplicação da lei supracitada 
Todavia, no do Direito do Trabalho a "pejotização" não é regulamentada, e sim considerada uma fraude a legislação laboral, essa modalidade passa então a ser objeto de intenso debate no âmbito judicial trabalhista, com a observância da questão caso a caso, conforme o contexto de prova produzido. Portanto, na Justiça do Trabalho a discussão acerca da "pejotização" traz à tona dois institutos: por um lado o emprego assalariado protegido pelo direito trabalhista, com a prevalência da figura do trabalhador hipossuficiente e, por outro, o trabalho autônomo, relação regulada pelo Direito Civil, em que há uma igualdade entre os dois contratantes.

\section{A UTILIZAÇÃo dA PEJOTIZAÇÃo PELOS HOSPITAIS NA CONTRATAÇÃo DOS MÉDICOS}

\subsection{Fraude}

A fraude ao contrato de emprego sucintamente seriam aquelas situações consubstanciadas no caput $\operatorname{artigo~}^{5} 9^{\circ}$ da legislação trabalhista a qual dispõe que serão nulos de pleno direito, os atos afins de desvirtuar impedir ou fraudar os preceitos celetistas. No caso da relação jurídica entre médicos e hospitais ela se demonstra no ato da contratação, na formulação do contrato, pois é nele em que se encontram as vontades das partes, nesse sentido devemos perceber, que no ato da formulação do contrato os hospitais exigem dos médicos a constituição de Pessoa Jurídica, na verdade fazem uma maquiação do contrato, afim de esconder uma vinculação de natureza empregatícia. Importante mencionar, o fato de as Leis Trabalhistas serem de natureza cogente, com natureza imperativa, pouco importa a intenção das partes na elaboração do contrato, mais sim a realidade a qual se encontram inseridos. Ademias na elaboração do pacto laboral, as partes devem guardar o princípio da boa-fé. (Maeda 2014) faz uma relação do princípio com a Ley de Contrato de Trabajo da Argentina (Ley n 20.744 - texto ordenado pelo Decreto 390/76) dispondo em seu artigo 63, que as partes estão obrigadas a trabalhar de boa-fé, ajustando sua conduta ao que é próprio de um bom empregador e de um bom trabalhador, tanto ao celebrar, executar ou extinguir o contrato ou a relação de trabalho. Portanto o princípio deve ser seguido e aplicado por todas as partes envolvidas no contrato de trabalho.

\footnotetext{
${ }^{5}$ Art. $9^{\circ}$ - Serão nulos de pleno direito os atos praticados com o objetivo de desvirtuar, impedir ou fraudar a aplicação dos preceitos contidos na presente Consolidação.
} 
O ordenamento jurídico Brasileiro, quando se depara com situações de fraude ao contrato de emprego pela pessoa jurídica, busca socorro nos princípios norteadores do Direito do Trabalho, os quais darão amparo aos conflitos dessa natureza, cabendo destaque aqui ao: princípio da imperatividade das normas trabalhistas (estando presente o vínculo empregatício não cabe ao trabalhador excluir a aplicação das normas trabalhista); princípio da irrenunciabilidade dos direitos trabalhista (ao empregado é vedado priva-se das vantagens e proteções que lhe asseguram as normas jurídicas); princípio da primazia da realidade.

Nesse sentido, o princípio que identifica a prevalência da verdade real sobre a forma é o princípio da primazia da realidade que servirá como norte identificador em situações fraudulentas. Sobre o princípio tema Pla Rodriguez (2000) orienta que as formalidades ou aparências, ou escritos em documentos, ou instrumentos não importa, mais sim a ocorrência pratica; sobre as simulações contratuais, orienta o autor que dificilmente quando ocorridas existe uma simulação absoluta ou total, ao contrário tais situações buscam obstruir o real conteúdo do contrato. A fraude contratual destaca o autor pode ocorrer de ambas as partes, bem como versar sobre vários aspectos, como carga horaria de trabalho, retribuições.

A constituição de pessoa jurídica pelos médicos não atenta somente contra o ordenamento trabalhista, haja vista que, com a menor arrecadação de Seguridade Social, Imposto de Renda de Pessoa Física, é lesado a sociedade em geral, na medida em que impossibilita a utilização desses recursos em prol da coletividade.

\title{
4.2 Ilicitude da Exigência
}

Resta por derradeiro neste último capítulo fazer uma pesquisa jurisprudencial, para entendermos como a Justiça do Trabalho tem se posicionado acerca da pejotização, foram analisadas decisões do TRT $9^{\circ}$, bem como o entendimento do TST acerca dessa fraude contratual.

\author{
Numeração Única: AIRR - 2127-61.2011.5.02.0383 \\ Desembargador Convocado: Américo Bedê Freire \\ Data de julgamento: 25/02/2015 \\ Data de publicação: 27/02/2015 \\ Órgão Julgador: $6^{\mathrm{a}}$ Turma \\ Ementa:
}

AGRAVO DE INSTRUMENTO EM RECURSO DE REVISTA. NEGATIVA DE PRESTAÇÃO JURISDICIONAL. VIOLAÇÃO DOS ARTIGOS 93, IX, DA CF/88, 832, DA CLT, E 458, DO CPC. PEJOTIZAÇÃO. ÔNUS PROBATÓRIO. ARTIGOS 331, DO CPC, E 818, DA CLT. REVOLVIMENTO DE FATOS E PROVAS. SÚMULA 126, DO TST. LIVRE CONVENCIMENTO MOTIVADO DO JUIZ. ARTIGO 131, DO CPC. A empresa alega que a decisão incorre em negativa de prestação jurisdicional e violação aos artigos 93, IX, da CF/88, 832, da CLT, e 458, 
do CPC. Ocorre que o Regional formou sua convicção com base em análise do conjunto probatório existente nos autos, expondo devidamente suas conclusões. Após analisar os documentos e a prova oral produzida, detectou nítida hipótese de pejotização, pois o reclamante foi incitado a constituir empresa, no único intuito de continuar a prestação de serviços já existente, descaracterizar a relação empregatícia e fraudar a legislação trabalhista. Opostos os embargos de declaração, o acórdão verificou que a empresa objetivou apenas a rediscussão da matéria posta em juízo, motivo pelo qual lhe negou provimento. No mérito, a recorrente nada mais quer do que a reapreciação do conjunto probatório existente nos autos e do próprio pleito inicial, uma vez que a presença dos elementos fático-jurídicos caracterizadores da relação de emprego, bem como da ocorrência ou não de pejotização, depende dos fatos constatados durante a instrução processual. Ocorre que, nos termos da Súmula 126, do TST, é "incabível o recurso de revista para reexame de fatos e provas". Não se pode esquecer que o Regional é soberano na análise de elementos fáticos e probatórios, tendo, no caso concreto, observado o princípio do livre convencimento motivado do juiz (art. 131, do CPC). Por fim, percebe-se que houve correta distribuição do ônus da prova, uma vez que a reclamada reconheceu a existência de prestação de serviço e confirmou a admissão do autor na qualidade de médico plantonista, atribuindo-lhe a condição de autônomo. Diante disso, a empresa atraiu para si o encargo probatório, a teor do disposto nos artigos 818 da CLT e 333, II do CPC, competindo-lhe o ônus de provar as suas alegações, do qual não se desvencilhou. Agravo de instrumento improvido.

O papel dos hospitais não se confunde com o papel do profissional médico, já que o ato médico é atribuição privativa do médico que não pode ser outorgada a estabelecimentos de saúde ou a terceiros. (...) na relação "hospital x médico e viceversa", nem sempre é o médico que vem a se inserir numa atividade do hospital, havendo situações em que é o hospital que serve de instrumental para que o médico possa desempenhar sua atividade fim, de forma autônoma. (TRT-PR-9556-2007-00809-00-8, Rel. Des. Marcio Dionísio Gapski, publ. em16/04/2010).

Das jurisprudências analisadas sobre a "pejotização" observou-se que a Justiça do Trabalho tem demonstrado que a utilização da empresa interposta individual tem servido para mascarar a relação de emprego. A empresa é constituída de fachada, na modalidade individual ou sociedade limitada, situação que os sócios aparecem como meros figurantes da relação, sendo por vezes a mãe, a esposa, o marido ou algum parente, para que o "véu" da formalidade afaste o estatuto salarial. Verifica-se que o empregado pejotizado é inserido no processo produtivo da atividade econômica da empresa contratante, desempenhando atividades imprescindíveis à consecução do empreendimento empresarial.

Desta feita, a Justiça do Trabalho tem comprovado que a contratação de uma pessoa jurídica para prestação de serviços vem sendo usada para substituir o contrato de emprego, na tentativa de descaracterizar o vínculo de emprego, através da utilização de um contrato de prestação de serviços de natureza civil.

Quando a Justiça do Trabalho constata que por trás da "pejotização" houve um trabalho prestado por pessoa física, com pessoalidade, de maneira não eventual, com onerosidade e subordinação, demonstra que tal relação trata-se de uma verdadeira relação de emprego. Assim, com base no art. $9^{\circ}$, da CLT, o Judiciário Trabalhista declara a nulidade da 
"pejotização", determinando o reconhecimento e o registro do contrato de emprego por parte da empresa contratante, além do pagamento dos direitos trabalhistas correspondentes.

Por outro vértice, quando detectado que no caso concreto houve uma empresa constituída de forma regular, com livre iniciativa da pessoa em constituir a pessoa jurídica, não existindo qualquer espécie de obrigação imposta por um terceiro, o contratante; que a pessoa assumiu integralmente os riscos econômicos decorrentes da criação dessa empresa, isto é, os lucros e os prejuízos; e que a pessoa por trás dessa pessoa jurídica era um verdadeiro prestador de serviços, um verdadeiro trabalhador autônomo, agindo com total liberdade e autonomia, a Justiça Trabalhista não reconhece o vínculo empregatício, ou seja, como a modalidade denominada de "pejotização" lícita.

Cabe mencionar que a ausência de lei ou a não edição de uma súmula ou OJ Orientação Jurisprudencial - consolidando o entendimento do TST - Tribunal Superior do Trabalho, de certa forma, proporciona liberdade ao empresariado para recorrer a tal prática e utilizá-la conforme seus interesses

\section{CONSIDERAÇÕES FINAIS}

Após discorrer sobre a pejotização e a fraude do contrato entre médicos e hospitais, pudemos evidenciar uma incidência de ocorrência desse fenômeno.

As fraudes nos respectivos contratos afrontam os princípios norteadores do Direito Do Trabalho, cabendo ao operador do direito identificá-las, e lutar pela garantia dos direitos trabalhistas face ao arbítrio do tomador.

A problematização do tema é de extrema dificuldade ao legislador, pois não se tem uma norma cogente, tendo o elemento subordinativo o principal diferenciador da existência ou não do vínculo empregatício. Vários autores definem a subordinação e suas formas ocorrentes no Direito Do Trabalho, foi buscado no presente artigo, uma síntese um norte, para análise do efeito da subordinação na relação entre médicos e hospitais.

Precipuamente e como marco distintivo da fraude no contrato, foi abordado a subordinação como elemento essencial para configurar o vínculo empregatício, concluiu-se que a subordinação aceita em nosso ordenamento é a jurídica, sendo ela o conjunto de ordens emanadas pelo tomador em seu grau de superioridade face ao obreiro, influindo diretamente as ordens e formas emanadas para prestação de serviços. 
Foram identificadas novas formas de subordinação, como a parasubordinação que estão no meio do subordinado e do autônomo. A subordinação cumulada com os demais requisitos caraterizadores do vínculo empregatício, podem vislumbrar o aspecto fraudulento do contrato, desvirtuando a natureza principiológica da proteção ao trabalhador. 


\section{REFERÊNCIAS}

BARROS, Alice Monteiro De. Curso De Direito Do Trabalho. 6a . ed; São Paulo: Ltr, 2010.

BEZERRA, Carlos Henrique Leite. Curso De Direito Do Trabalho. 5a . ed., São Paulo:

Saraiva, 2013.

CAIRO JUNIOR, José. Curso De Direito Do Trabalho. 2a . ed., Salvador: Jus

Podivm, 2008.

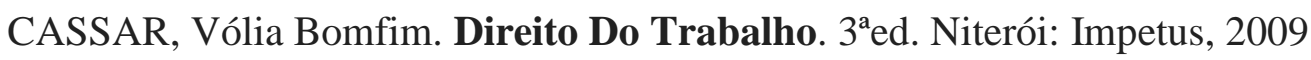

DELGADO, Mauricio Godinho. Curso De Direito Do Trabalho. $13^{\text {a }}$. ed., São Paulo: LTr, 2014.

, Gabriela Neves Delgado. Reforma Trabalhista no Brasil: com os comentários à Lei n. 13.467/2017. - São Paulo: Ltr, 2017.

FERREIRA Aurélio Buarque de Holanda. Novo dicionário da Língua Portuguesa. 2.ed.Rio de Janeiro: Nova Fronteira, 1986. p. 1621

LEITÃO, André Studart; BRUNETTA, Cíntia; FILHO, Fernando Sergio Studart Leitão. Vidas Esquecidas: Reforma Psiquiátrica, Dignidade e Desinstitucionalização. Revista Juridica, [S.1.], v. 53, n. 4, p. 255 - 274, fev. 2020. ISSN 2316-753X. Disponível em: <http://revista.unicuritiba.edu.br/index.php/RevJur/article/view/3218/371371735>. Acesso em: 19 abr. 2020. doi:http://dx.doi.org/10.21902/revistajur.2316-753X.v53i4.3218.

MARTINS, Sergio Pinto. Curso de Direito Do Trabalho. 6ª .ed., São Paulo: Atalas, 2014.

MAEDA, Fibíola Mioto. Prestação de serviço por meio de pessoa jurídica: dignidade e fraude nas relações de trabalho. 149 f. Dissertação (Mestrado em Direito do trabalho e dignidade social - Faculdade De Direito da Universidade de São Paulo, São Paulo, 2014.

MARTINEZ, Luciano. Curso De Direito Do Trabalho. 4ª ed., São Paulo: Saraiva, 2013.

NASCIMENTO, Amauri Mascaro. Curso de Direito do Trabalho.18 a . ed., São Paulo: Saraiva. 2003.

PEREIRA, Leone. Pejotização: O Trabalhador Como Pessoa Jurídica. São Paulo: Saraiva, 2013.

PLA, Rodrigues, Americo. Princípios Do Direito Do Trabalho. 3ª ed. São Paulo: Ltr, 2010 
